\title{
Why the EFSUMB guidelines in musculoskeletal ultrasonography are necessary?
}

\section{Daniela Fodor}

$2^{\text {nd }}$ Internal Medicine Department, “Iuliu Hatieganu” University of Medicine and Pharmacy, Cluj-Napoca, Romania

Musculoskeletal ultrasonography (MSUS) has become a widely used technique in rheumatology, orthopaedics, sports medicine, rehabilitation medicine, radiologists, and many other medical specialities. The technique is recognized as a dynamic, multiplanar, patient-friendly, easily and bedside available diagnostic imaging method. Also, US details relevant anatomical and pathological conditions of the cortical bone and soft tissue structures, can assess multiple joints, provides high-resolution and real-time images on multiple plans and is less expensive than other imaging methods. Its sensitivity and specificity are higher than the clinical examination's and, in many situations, its ability for detecting the real pathology is comparable to the magnetic resonance imaging (MRI). The utility of MSUS for the diagnosis, management and monitoring of the musculoskeletal disorders is largely recognised and all these are emphasized by the possibility of efficiently guiding the local therapy or biopsy.

The number of publications related to the MSUS has grown exponential in the last years, the research being stimulated by the numerous developments of the technology (for example: high-quality US machines or high-frequency transducers - more than $24 \mathrm{MHz}$, new US techniques such as elastography or contrast enhanced US). The increased quality of Doppler techniques transformed the MSUS in the preferred imaging technique used for inflammation evaluation.

Received Accepted

Med Ultrason

2020, Vol. 22, No 4, 391-392

Corresponding author: Daniela Fodor MD, $\mathrm{PhD}$

$2^{\text {nd }}$ Internal Medicine Department

"Iuliu Hatieganu" University of

Medicine and Pharmacy,

2-4 Clinicilor street,

400006 Cluj-Napoca, Romania

E-mail: dfodor@umfcluj.ro
The high interest in using MSUS in the daily professional life was stimulated also by the medical scientific societies, by organizing courses, workshops or congresses [for example the European League Against Rheumatism (EULAR), European Society of Musculoskeletal Radiology (ESSR) or European Federation of Societies for Ultrasound in Medicine and Biology (EFSUMB) in Europe]. In the last years, many clinical practice guidelines or position statements regarding MSUS were published [1-9]. Being considered an operator-dependent technique, standardization of the US was a matter of debate over the years. The work of OMERACT (Outcome Measures in Rheumatoid Arthritis Clinical Trials) was very important for publishing expert consensus on MSUS definitions for normal and pathological findings, these definitions being considered to form a standardized nomenclature in the present [10].

Taking in consideration the huge number of MSUS indications and the multitude of medical specialities that have been using the technique, the necessity for a common position among MSUS experts became obvious. The synovitis, tenosynovitis, muscle trauma, ligament tears, nerve compressions, bone erosions, fascial thickening or subcutaneous nodules have the same US aspect, irrespective of the speciality of the performing examiner.

For this reason, EFSUMB, an organisation in which US is 4all, brings together experts from different specialities and medical scientific societies in order to elaborate generally valid recommendations for the use of MSUS. After discussions and consultations inside the EFUMB Executive bureau and in the steering group, 35 representative personalities of the MSUS from 15 countries across Europe were invited. The group has been working for more than 10 months and now is close to completing the task.

The recommendations are based on an extensive literature review. The literature research included the papers 
that have been published in the last 20 years, a period that we considered to be the most representative for the knowledge in MSUS. A recommendation level was suggested for each guideline based on the published literature. The Oxford Guidelines for reporting medical evidence was used, specifying the level of evidence (LoE) and the grade of recommendation (GoR) [11] and the entire process have followed the principles and the methodology of EFSUMB in creating the Clinical Practice Guidelines [12]. Finally, the guidelines will be adopted after the level of consensus of the members in the task force group will be established following a Delphi process.

What we expect from these guidelines and recommendations? A uniformity in the way that MSUS is viewed, used and, particularly, an increased confidence in its results.

\section{References}

1. Janta I, Terslev L, Ammitzbøll-Danielsen M, et al. EFSUMB COMPASS for Rheumatologists dissemination and implementation--an international survey. Med Ultrason 2016; 18:42-46

2. Mandl P, Ciechomska A, Terslev L, et al. Implementation and role of modern musculoskeletal imaging in rheumatological practice in member countries of EULAR. RMD Open 2019;5:e000950.

3. Möller I, Janta I, Backhaus M, et al. The 2017 EULAR standardised procedures for ultrasound imaging in rheumatology. Ann Rheum Dis 2017;76:19741979.

4. Plagou A, Teh J, Grainger AJ, et al. Recommendations of the ESSR Arthritis Subcommittee on Ultrasonography in
Inflammatory Joint Disease. Semin Musculoskelet Radiol 2016;20:496-450 .

5. Sakellariou G, Conaghan PG, Zhang W, et al. EULAR recommendations for the use of imaging in the clinical management of peripheral joint osteoarthritis. Ann Rheum Dis 2017;76:1484-1494.

6. Sconfienza LM, Albano D, Allen G, et al. Clinical indications for musculoskeletal ultrasound updated in 2017 by European Society of Musculoskeletal Radiology (ESSR) consensus. Eur Radiol 2018;28:5338-5351

7. Siddle HJ, Mandl P, Aletaha D, et al. The EULAR points to consider for health professionals undertaking musculoskeletal ultrasound for rheumatic and musculoskeletal diseases. Ann Rheum Dis 2018;77:311-313.

8. Tagliafico AS, Wilson D, Sconfienza LM; European Society of Musculoskeletal Radiology (ESSR) Research Committee. Encouraging MSK imaging research towards clinical impact is a necessity: opinion paper of the European Society of Musculoskeletal Radiology (ESSR). Eur Radiol 2019;29:3410-3413.

9. Uson J, Loza E, Möller I, et al. Recommendations for the Use of Ultrasound and Magnetic Resonance in Patients With Spondyloarthritis, Including Psoriatic Arthritis, and Patients With Juvenile Idiopathic Arthritis. Reumatol Clin 2018;14:27-35

10. Wakefield RJ, Balint PV, Szkudlarek M, et al. Musculoskeletal ultrasound including definitions for ultrasonographic pathology. J Rheumatol 2005;32:2485-2487.

11. Phillips B, Ball C, Sackett D et al. Oxford Centre for Evidence-based Medicine - Levels of Evidence 1. In. Oxford: Oxford Centre for Evidence-Based Medicine;2009

12. Jenssen C, Gilja OH, Serra AL, et al. European Federation of Societies for Ultrasound in Medicine and Biology (EFSUMB) Policy Document Development Strategy - Clinical Practice Guidelines, Position Statements and Technological Reviews. Ultrasound Int Open 2019;5:E2-E10. 